\title{
Focus in Honor of Carol V. Robinson, 2003 Biemann Medal Awardee
}

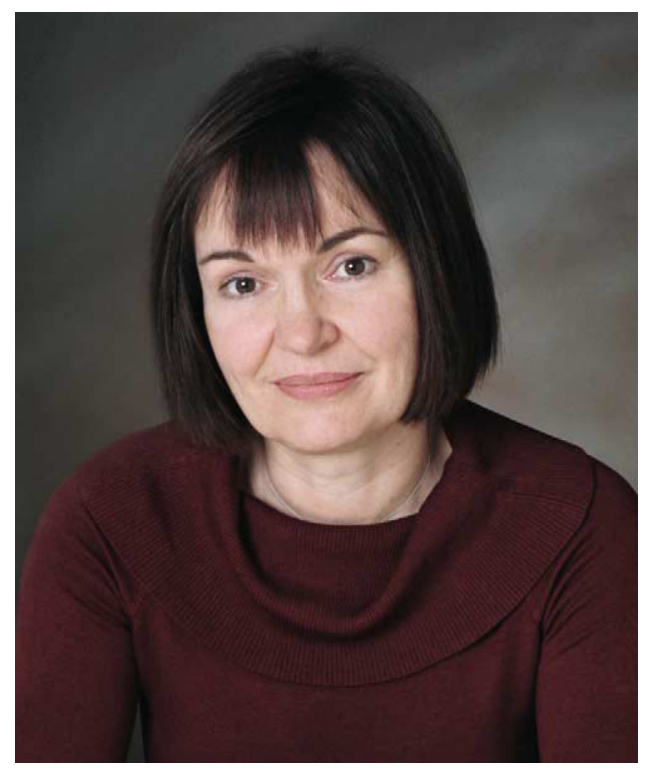

Figure 1. Carol Robinson (Photo by Nathan Pitt).

The Biemann Medal recognizes a significant achievement in basic or applied mass spectrometry made by an individual early in his or her career. The award is presented in honor of Professor Klaus Biemann and is endowed by contributions from his students, postdoctoral associates, and friends. The 2003 Medal was presented to Professor Carol V. Robinson (Figure 1) of Cambridge University for her achievements and contributions to the areas of protein mass spectrometry and structural biology (Figure 2).

Carol received her Master of Science degree under the tutelage of Professor John Beynon at the University of Wales, Swansea and her Ph.D. degree from Cambridge University under the supervision of Professor Dudley Williams. Carol's research career has always been focused on the mass spectrometric analysis of large biomolecules. Shortly after the initial report in 1981 by Barber and colleagues on the development of fast atom bombardment (FAB), Carol (then as Carol Bradley) co-authored several papers on the application of FAB for the study of polar molecules, including antibiotics and peptides. I recall learning a little about Carol's early career when we both participated in a small Biotechnology Symposium at the Max Planck Institute for Experimental Medicine in Göttingen, Germany in 1997. In the 1970s, she started work as a

Published online August 27, 2004 technician at Pfizer Pharmaceutical (in Sandwich, UK), where she began to be exposed to mass spectrometry. This propelled Carol to pursue further training in the field of mass spectrometry. After receiving her degrees and after an eight-year hiatus while her children were young, she received a Royal Society Research Fellowship in 1995 and assumed the position of Director of Mass Spectrometry at the Oxford Centre for Molecular Sciences. In 1999 she became one of the youngest professors and also one of only 17 women with the title of Professor at Oxford University. She moved recently to Cambridge University, where she holds the rank of University Professor in the Department of Chemistry.

Mass spectrometry has become a technique to study the structure and dynamics of macromolecules and to describe their folding and assembly, largely because of the pioneering work of Carol Robinson. Her initial studies beginning around 1993 revealed the power of MS in the study of protein folding. She showed that a combination of MS and NMR provided key information about the cooperative nature of the folding process and folding intermediates. She used hydrogen/deuterium exchange to probe the accessibility of regions of individual proteins and components of complexes, and to map association surfaces. Such information provided a unique insight into the nature of the dynamical processes occurring within protein molecules. She went on 


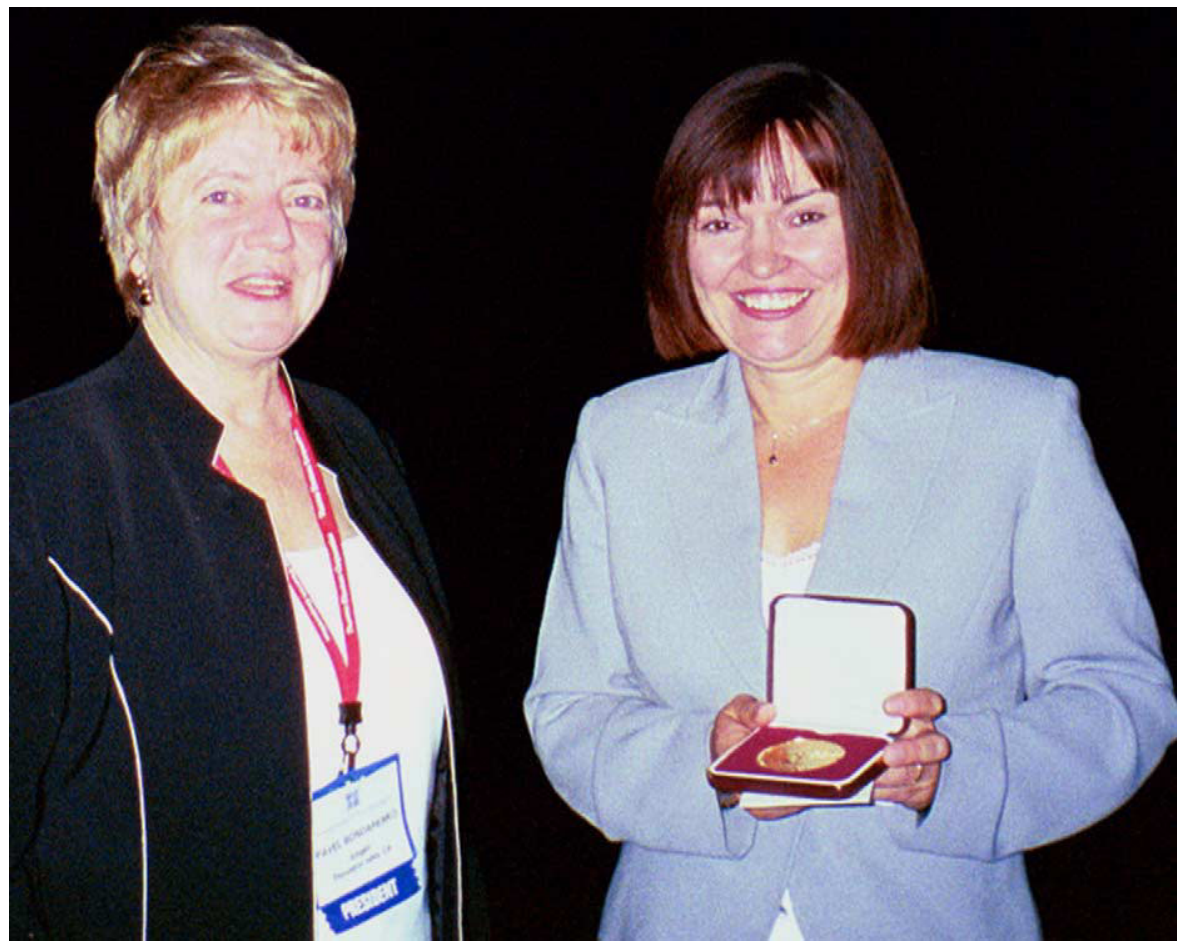

Figure 2. Carol Robinson (right) receiving the 2003 Biemann Medal from Cathy Costello, ASMS President at the 2003 ASMS Conference in Montréal, Quebec, Canada. (Photo courtesy of Susan Weintraub.)

to study the way in which folding intermediates interact with molecular chaperones such as $800 \mathrm{kDa}$ GroEL and carried out pioneering work in this area.

Carol's more recent work has focused on the nature of the interactions and mechanisms of noncovalent assembly. In the early 1990s, Bruce Ganem and Jack Henion at Cornell University showed first that electrospray ionization is sufficiently gentle to maintain weakly bound macromolecular complexes, demonstrating interactions between FK binding protein and macrolides rapamycin and FK506, and the enzyme-substrate pair of lysozyme and N-acetylglucosamine. Brian Chait and Vish Katta shortly thereafter demonstrated the detection of the myoglobin-heme complex using ESI-MS. Some in the pharmaceutical industry, including myself at Parke-Davis/Pfizer and Birendra Pramanik at Schering-Plough, were exploiting this feature of ESI-MS to study protein-ligand interactions and to develop the method as a means to screen compounds for drug discovery. Others, including Dick Smith at Battelle-Pacific Northwest National Laboratory and Steve Naylor at the Mayo Clinic, were using ESI-MS for studying DNA-DNA and DNA-protein interactions. The first to illustrate the potential for examining very large noncovalent complexes was Ken Standing and his merry mix of Canadian and Russian researchers at the University of Manitoba. Using a time-of-flight (TOF) analyzer, protein complexes in excess of $300 \mathrm{kDa}$ were measured. Although some of us suspected that the cold air of Canada was playing a role in stabilizing such large, gas phase molecules, earlier work by John Fenn had suggested that very large molecules could be ionized by ESI. A Journal of the American Chemical Society (JACS) paper published in 1992 by Fenn demonstrated that polyethylene glycol of molecular weight 5 million could be ionized and measured by MS. Little did we suspect that biomolecular complexes of such size and held together by weak forces could be ionized and measured as intact entities. Carol's work in this arena has captured the imagination and the admiration of a large section of the biology community and has helped to convince them of the power of mass spectrometry.

Carol has the impressive ability to identify important problems in structural biology and to identify experimental strategies to address the central issues. She and her research team have developed both the methodologies and the equipment that enable such studies to be carried out. She has shown that it is possible to investigate complexes of unprecedented size, including the 2.3 MDa ribosome and intact viruses. With the aid of Micromass, a high mass-to-charge range quadrupoletime-of-flight (QTOF) analyzer was developed specifically for tandem mass spectrometry studies of large protein assemblies. The application of MS/MS has been especially helpful for defining macromolecular complexes of unknown stoichiometry and structure. She has studied complexes associated with protein misfolding and aggregation and contributed substantially to our understanding of amyloid diseases.

For those fortunate to have listened to one of Carol's 


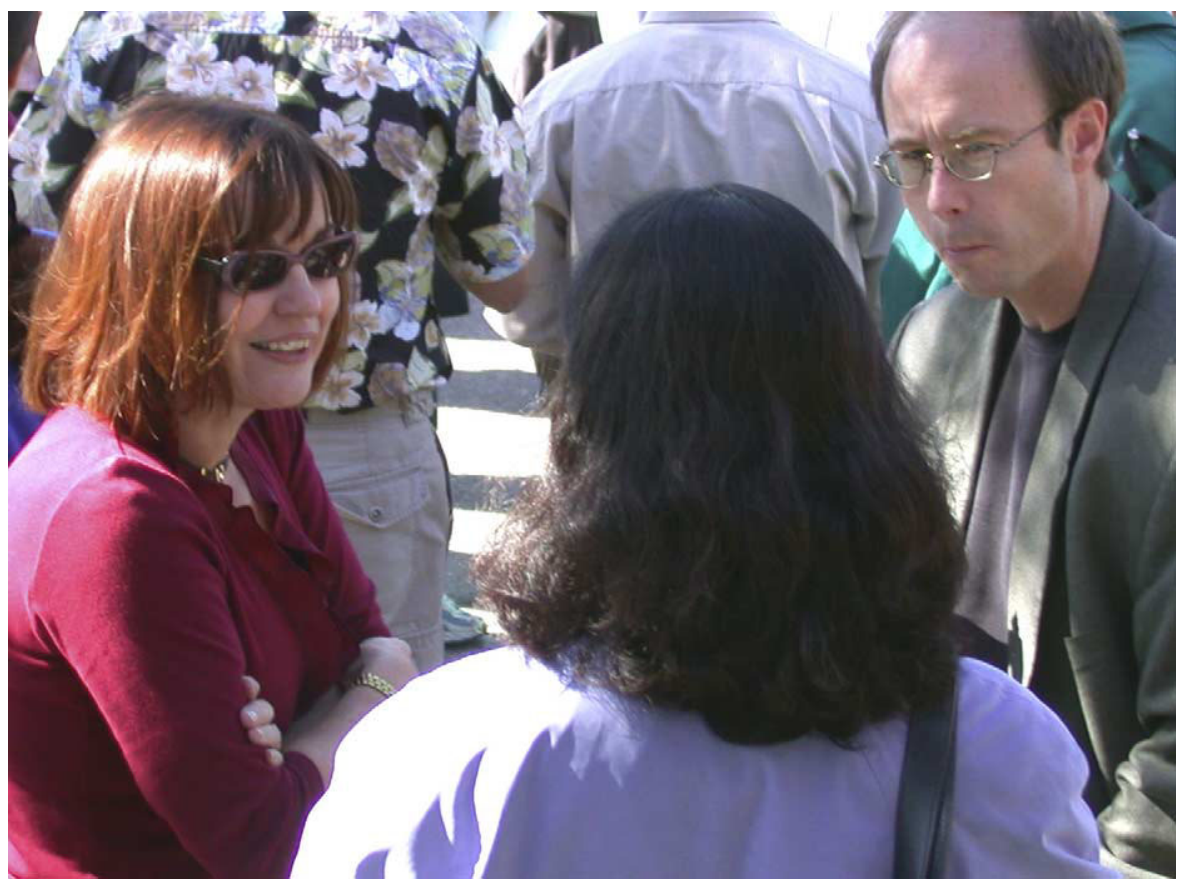

Figure 3. During a break at the 2003 Asilomar Conference, Carol Robinson (left, dark glasses) discusses with Jeffery Kelly (Scripps Research Institute, right) and an unidentified scientist the role of ESI-MS to study the mechanism of amyloid diseases.

lectures, what has always been impressive is her ability to highlight the significance of the underlying biology and marry it to the analytical science. Often she will show a beautiful picture from a high-resolution structure of a protein complex, followed by the ESI mass spectrum that not only confirms the existence of the interaction, but also suggests other subtle features about the nature of the interaction missed by other biophysical probes. She has been an advocate for studying the forces that govern the interactions not only in solution, but also in the gas phase. Her solid publication record of over 120 papers mirrors her interests in both biology and chemistry, as it includes three articles in Nature, one report in Science, five papers in the Proceedings of the National Academy of Sciences USA, and seven papers in JACS. Carol is also an Associate Editor for both JASMS and Protein Science. For her outstanding contribution to natural science and technology, in addition to the Biemann Medal, Carol has been very recently awarded the second annual Rosalind Franklin Award, which was bestowed by the Royal Society, the national academy of science of the United Kingdom. Nearly simultaneously, Carol was elected a Fellow of the Royal Society.

The series of articles honoring Carol's achievements reflect her contributions in protein mass spectrometry. In the Fall of 2003, I had the pleasure to co-organize with Carol the 19th Asilomar Conference on Mass Spectrometry on biomolecule interactions, and the identification and characterization of protein complexes (Figure 3). Many of the presenters at the Asilomar Conference have contributed an article to dedicate Carol's award. Three of the papers (by Jennifer Beck and Margaret Sheil, University of Wollongong; Frank Pullen, Pfizer and Albert Heck, Utrecht University; Julie Leary, University of California, Berkeley) describe the use of ESI-MS for studying protein or DNA interactions with ligands. Evan Williams (University of California, Berkeley) presents further studies on the origins of asymmetric charge partitioning observed in tandem mass spectrometry of dimeric protein complexes. A discussion on the dynamic range limit of detection by ESI-MS is presented by Dick Smith's group (Pacific Northwest National Laboratory). Paul Kebarle (University of Alberta) contributes an article on the mechanism of ESI as it relates to the measurement of noncovalent protein complexes. Mike Bowers (University of California, Santa Barbara) discusses the conformation and aggregation behavior of $\alpha$-synuclein, a protein that plays a role in Parkinson's disease.

Professor Klaus Biemann's career was dedicated to the development of mass spectrometry and its application in a variety of diverse fields, including chemistry and biology. It is entirely fitting that the Biemann Medal was awarded to Carol Robinson, who has without question continued the legacy and high standards established by Professor Biemann.

Joseph A. Loo

University of California, Los Angeles, Los Angeles, California, USA

Focus Arranged by Michael L. Gross,

Editor

Washington University, St. Louis 